\title{
Protection of Abused Children, the Mentally and Physically Challenged, and the Elderly
}

The Miami Herald headlines screamed that fiveyear-old Reyla Wilson was missing and no one had seen her for almost two years. Where is she? How can the Florida Department of Children and Families have lost a foster child in its custody? In New Jersey the Newark Star Ledger also had screaming headlines accusing the New Jersey Department of Children Youth and Families of failing to protect two little boys in its care each killed by a caretaker. In city after city the headlines tell the story of children who are killed by family members. Isn't the child protective services system supposed to prevent this from happening?

\section{Introduction}

The duty to protect children and other vulnerable populations (those who cannot protect themselves) is delegated to each state's child and family protective services agency. These agencies might be named differently from one state to the next, such as child protective services (CPS), Department of Children and Families (DCF), Department of Child and Family Services (DCFS), Department of Social Services (DSS), or Department of Human Services (DHS), among others. For consistency in this chapter, we will primarily refer to CPS or DCF, or to the more general "protection system." Of course, as we suggest throughout this book, we encourage you to look up your own state's agency terminology and keep in mind how there might be differences as you read through the following sections.
The protective agencies such as DCF operate as a part of each state's division of U.S. Health and Human Services, and they must follow their state's respective laws as well as applicable federal laws. As we noted before, these agencies are tasked with protecting citizens who cannot protect themselves from harm, generally children, the elderly, and those who because of mental incompetence (often defined as intellectually limited, neurologically impaired, or severely mentally ill) as well as other disabilities. In this chapter, we will provide an overview to explain the system, review definitions that vary from state to state and under federal law, and discuss its benefits and drawbacks.

One of the cornerstones of the protection system is the mandated reporting laws that require mental health professionals and others specified in the statutes to report any suspicion that those covered by the laws are being harmed. The precise definitions are discussed below, and, predictably, each state has slightly different requirements for their mandated reporters. For example, in Florida, a report must be made within $24 \mathrm{~h}$ of learning reasonable suspicion of abuse that is occurring, while other states may have different timelines. As might be imagined, these reporting statutes also have their benefits and limitations. To make matters even more complicated, the protection system must interact with the criminal justice system and family law systems when there are cases that are filed in 
these divisions, also. In some districts, there has been a movement toward a Unified Family Court where all three divisions can come together and dispose of cases within the same family to streamline the proceedings.

Let's look at a quick overview: the child and family protection system directly investigates reports of child abuse, abuse of the elderly, and harm to others who cannot protect themselves and provides them with appropriate services. It also deals with the prevention of further harm by overseeing a system of foster care and homes for children, adults, and the elderly, which are usually called assisted living facilities (ALFs). The foster care system where children are placed after being removed from their homes is divided into family (or "kinship") care and approved foster homes. Since many of these children's parents or relatives continue to be unable to care for them even after services are provided, this may lead to their adoption, so adoptions are also placed in this division of the legal system. Finally, many of these individuals need treatment to overcome the effects of trauma, so the regulation of residential treatment centers is also assigned to this court.

As might be expected, the numbers of cases of abuse overwhelms the system. In 2001, approximately 4.1 million referrals concerning the welfare of over 7 million children were reported to CPS agencies across the country as suspected of being abused or neglected. In roughly $16 \%$ of those reports, the investigation found a child to be at risk, or already abused and maltreated. Although the rates of reporting suspected abuse have been increasing, cases of finding actual maltreatment appear to be on the decline overall. The National Clearinghouse on Child Abuse and Neglect Information serves as a resource for national data on child maltreatment reports and publishes the National Child Abuse and Neglect Data System (NCANDS) and National Incidence Study of Child Abuse and Neglect (NIS) at regular intervals. These are updated regularly and are available at their website, which would be an excellent resource if you're looking for more specific information or detail than is provided here (https://www.childwelfare.gov/topics/ systemwide/statistics/nis/).
States also must provide services for children who have special needs. To fulfill this mandate, the social services systems interact with the school systems and medical facilities on behalf of these children. When they are out of school, the state has the responsibility of providing adult vocational training programs, daycare centers, and residential facilities in addition to the ALFs mentioned earlier. In most states, the protection of the elderly comes under the same department's care and protection. Probate court, which determines competency to care for one's basic needs, may also become involved when abuse reports are made. To further complicate the picture, if abuse is determined to have occurred toward anyone in this system's care, the state may also file criminal charges against the abusive parent or caregiver, adding a third legal proceeding with yet a different standard of proof required.

\section{Definitions}

\section{Child Maltreatment}

As we have seen in other chapters where definitions of an act are based on law, each state and the Federal government have slightly different definitions here as well. In some cases, there will be laws passed by Congress that suggest states follow a particular definition, but these usually are only guidelines to be sure all the elements are covered. "Child maltreatment" is the term used to cover all forms of physical abuse, sexual abuse and exploitation, neglect, abandonment, medical neglect (although usually not if caused by poverty or religious beliefs), psychological and verbal abuse, corporal punishment, and intentionally or unintentionally committing, causing or permitting actual harm or threats of harm to a child. In 2017 , almost 675,000 children were found to have been maltreated. Slightly more girls (51\%) than boys (48.6\%) were reportedly abused. About $44 \%$ of the victims were white, with about $22 \%$ Hispanic and about 21\% African American. Overall the rate of abuse is inversely related to the age of the child with children from ages birth to 3 representing $28 \%$ of the victims. In 2017 , 
1688 children died of child maltreatment, with the youngest children being the most vulnerable. Nearly one-half of the deaths were children under the age of one year and $74 \%$ of the children who died were under the age of three (United States Department of Health and Human Services, 2019).

\section{Physical Abuse}

Physical abuse of a child is defined as inflicting physical injury on a child by hitting, kicking, punching, beating, throwing, biting, burning, starving, or otherwise physically harming a child. The injury may be a result of one severe incident or cumulative from several injuries. The trauma can be minor, resulting in bruises and abrasions, or major, with injury to internal organs such as the liver or head trauma. Physical abuse of a child also includes bizarre forms of abuse such as locking a child in a room or closet for days/weeks at a time, forcing participation in satanic cult-type rituals, tying a child up to restrict all movement for long periods of time, and forcing the child to drink so much water that his or her electrolytes are disrupted. Physical abuse also includes the use of torture such as electrical stimulation with cattle prods, confinement in a coffin, and forcing the child to walk for long distances in the cold until the child drops from exhaustion. As you can see, child physical abuse encompasses much more than the commonly thought-of hitting or kicking. Almost onefifth $(18.3 \%)$ of the child abuse cases reported in 2017 involved physical abuse, with approximately $41 \%$ of child abuse-related fatalities coming from the physical abuse category.

\section{Sexual Abuse and Exploitation}

Sexual abuse includes a very broad range of behaviors that range from exposure of the genital area, to inappropriate touching or fondling (with or without clothes), and forcing or coercing the child to perform sex acts (whether or not the child stated they "wanted" to participate), including digital, manual, oral, or penis-vagina penetration. Sexual exploitation includes the above, prostitution, electronically recording, and selling pictures of the child commercially,
Internet child pornography, or other ways of sexually interacting with a child and others. It is not difficult to imagine the complications that have arisen, from an investigation and prosecutorial standpoint, as a result of Internet advances and social media. Parents and caregivers are the most frequent child sex abusers. Although there are some treatment programs for abusers, rarely are they successful unless they have relapse prevention components that include no contact with children. We discuss this further in other chapters.

While incest between fathers and daughters or sons is the most frequently reported form of child sexual abuse, others in a position of authority have also abused and exploited children. This includes athletic coaches, teachers, and religious leaders. The headlines have become more padded with breaking stories concerning the sexual abuse and exploitation of children. The large numbers of altar boys who were sexually abused by priests in the Catholic Church is an example of how a hierarchical network of priests could and did cover up this abuse, sending priests known to have committed child sexual abuse to another community where they had access to even more children. In recent years, we have seen the names of famous comedians such as Bill Cosby, sports icons like Jerry Sandusky and Joe Paterno, wealthy icons such as Jeffrey Epstein, and physicians such as Larry Nassar of U.S. Gymnastics gracing the news, always with heartbreaking stories of widespread sexual abuse of minors. But we must remember that sports teams or public areas are not the only places children are targeted. Children may be abused in groups or individually, in homes, cars, churches, schools, swimming pools, locker rooms, or anywhere that children are found. They may also be forced into ritual and satanic abuse or other bizarre activities that sound unbelievable but have been known to occur. We shall discuss the damage that occurs when children are sexually abused later. Approximately $9 \%$ of children who were reported as abused in 2017 were found to have been sexually abused (United States Department of Health and Human Services, 2019). 


\section{Emotional or Psychological Abuse}

Emotional abuse, also often called psychological abuse, is defined as acts or omissions that caused, created, or threatened to cause serious emotional, cognitive, behavioral, or mental disorders in a child. These acts or omissions are usually made by parents, relatives, or caregivers, although the definition surely does not limit the actions to only caretaking figures. It includes a number of behaviors on a continuum from belittling a child, cursing and name calling, making damaging derogatory comments, scapegoating, and humiliating, to isolating, screaming, raging, and rejecting the child. Indeed, even the witnessing of these behaviors toward another person in the child's environment, such as in cases of domestic violence where the child is never actually targeted by either physical or verbal behaviors like those described, can have significant psychological impact on a developing child (Walker, 2017). For this reason, several jurisdictions now consider failure to protect a child from witnessing domestic violence as emotional abuse. Emotional abuse cases accounted for nearly $6 \%$ of the cases reported (United States Department of Health and Human Services, 2019).

\section{Child Neglect}

Child neglect is not providing for the child's basic needs, and it falls into different categories based on what type of needs are not being met: physical (such as food or shelter), educational (such as getting or keeping a child in school, or providing resources such as class materials), emotional (which includes, for examples, withholding of all affection or attention, or not speaking to a child for lengthy periods of time), and medical (such as withholding medical treatment for illnesses or injuries). Usually, not providing something the child needs because of poverty or religious belief is not considered child abuse, although it may harm the child. In cases where poverty is determined to be the reason for neglect, state protective systems will often still step in and provide resources and assistance to help a family, as opposed to removing a child from a parent's care, unless there is imminent risk of harm of death. Take as an example a child born with birth defects who is prescribed specialized medications and medical procedures requiring expensive equipment that must be maintained. While the state may recognize that medical neglect, in this case, might be due to poverty or lack of education, the system will not leave a child in place in a home where they do not receive the necessary care while helping the parents to bolster their financial ability to care for their child. Instead, the child would be placed in a specialty foster home while services are provided for the family. As you can surely imagine, cases involving religious beliefs are quite complicated and create murky legal waters, as the system aims to respect a family's religion while also maintaining their responsibility for child safety. More mothers are found guilty of child neglect than of physical or sexual abuse of the child. Neglect cases accounted for roughly $75 \%$ of the child abuse cases reported in the U.S. in 2017 (United States Department of Health and Human Services, 2019).

\section{Abuse of the Elderly}

Although there are different statutes that protect the elderly from abuse and neglect, the illegal acts are similar to those listed above for child abuse. In the elderly, the most frequent abusers are caregivers and adults responsible for the care of elderly parents and grandparents. These could be younger family members such as children, grandchildren, or nieces and nephews, or the caregivers could be trained professionals who work in ALFs or as home health aides or medical professionals. Indeed, recent stories about the state of the ALFs mentioned throughout the chapter highlight the concern about abuse in these facilities. In the wake of Hurricane Irma in 2017, several elderly residents of a South Florida nursing home died of complications of heat exhaustion when the residents were not moved from a powerless facility where no generator was running for days (an extreme example of neglect). During the corona virus pandemic in 2020, ALFs and nursing homes accounted for about half the deaths for a variety of reasons. However, if we looked more closely at physical abuse cases, we would also likely find a 
high rate of elderly husbands who are still abusing their elderly wives. On the other hand, there may also be high numbers of elderly men who are being abused by wives whom they previously abused when they were stronger and less vulnerable. Given the graying of America and the rise in the numbers of the very old who need adequate care facilities, there is great and growing interest in preventing elder abuse by exploitation, neglect, starvation, medical neglect and malpractice as well as physical maltreatment.

\section{Impact from Abuse}

Child maltreatment has known detrimental effects on the physical, psychological, cognitive, and behavioral development of children that lasts long into adulthood. An important study of Adverse Childhood Experiences (ACEs) was conducted by the Centers for Disease Control (CDC) and found significant damage to the participants health and lifestyle (Felitti et al., 1998). These consequences range from minor to severe and include physical injuries, brain damage, low self-esteem, problems with attachment in relationships, developmental delays, learning disorders, mental illness, and aggressive behavior. Some of the mental illnesses associated with child abuse include post-traumatic stress disorder (PTSD), depression, anxiety, borderline personality disorder, conduct disorders, and substance abuse disorders. In more serious cases of child sexual abuse, we have evidence of dissociative disorders and even schizophrenia spectrum disorders that have developed. Many physical illnesses have known association with childhood abuse, including (but surely not limited to) those that involve a breakdown of the immunological system such as Lupus, Fibromyalgia, and cancer. New studies have demonstrated the impact of abuse on the brain development of children, showing evidence that childhood abuse can result in structural changes to the brain and its future development, which can have far-reaching impacts throughout life. These impacts can include the child's educational and career aspirations as well as emotion regulation, interpersonal relationships, and decision-making capacities. Not surprisingly, the percentages of people in prison for all types of crimes who were abused or maltreated as a child number close to $85 \%$. It seems that putting some more money into prevention and early intervention programs might save significant resources-both financial and emotional — on the other side.

\section{Costs of Maltreatment}

Direct costs of child maltreatment reflect the dollars spent by the child welfare, judicial, law enforcement, health, and mental health systems as a result of the maltreatment. According to the Centers for Disease Control (CDC), the estimated annual cost of child maltreatment was a staggering $\$ 124$ billion (2012). This includes the costs of protective services, foster care, legal and law enforcement costs, health costs of low birth weight babies, medical treatment of injuries from abuse and other mental health services (such as evaluations and classes for parents, discussed later), special education costs, early intervention, psychological care for maltreated children, juvenile justice system and correction services, and adult criminality. In addition, indirect costs include lost wages, lost sales tax from children's deaths, teen pregnancies, welfare dependents, domestic violence, and other problems, bringing the totals to unfathomable amounts of money that must be spent on a cycle of abuse that continues to repeat itself. This does not include the money spent on child custody and visitation battles raised by domestic violence perpetrators, who themselves had a high rate of exposure to child abuse. Various groups have tried to place dollar amounts on the total cost of maltreatment as a way of influencing policy-makers to put more money in the front end to prevent or treat early abuse.

\section{Foster Care, Adoption, and Fitness to Parent}

One remedy to stop child abuse by a parent is to remove the child from the parent's home and place the child in foster care or kinship care, 
which you may recall means the child is living with a non-parent familial relative. The state delegates the authority to CPS to take custody of the child and provide for their needs while "sheltering" the child. Some CPS agencies handle their own foster placement systems or networks, while others contract out to companies or other agencies who license and coordinate foster parents. While the child (ren) is in foster care or kinship care, CPS will provide case plans or treatment plans to the parents, outlining a list of required services (psychological evaluations or parent training classes, for example) and other mandated actions such as securing safe and suitable housing, if this was at issue. During this time, the children and parents will have scheduled visitation opportunities, and these may be unsupervised, supervised by a family member or CPS, or therapeutic supervised, which we elaborate on later.

The court oversees how CPS handles each case by demanding reviews on a regular basis after the initial treatment plan is approved (sometimes monthly, sometimes every two or three months depending on how long a child has been sheltered by the state, how the child is adjusting and handling the circumstances, and how the parents are proceeding through their case plans). One problem that was raised in the earlier chapter on custody and visitation is the mandate for the reunification of the family, in this case between the offending parent and the child. If the parent does not complete the reunification plan, for a variety of reasons, then the children may be placed for adoption. Each state designates a different timeframe for when they expect reunification to occur by, although exceptions can and are frequently made in order for the state to make every possible effort to reunify biological families. As you can imagine, in some rather sad examples, cases can become drawn out based on legal challenges and children can languish in the foster care system for extended periods of time, sometimes even several years in extreme cases.

\section{Fitness for Adoption and Foster Parenting}

A special area that differs some from custody determinations where one or both parents are the biological ones occurs when families are trying to raise children who are not related by blood. In many states, relatives who wish to care for a child can apply for "kinship care" and can step into the fostering role while children are sheltered by the state, or they can request to adopt the child if the court refuses to reunify the child and parents. Sometimes the state grants financial assistance to these relatives in order to promote the continuation of family ties. However, careful psychological evaluation of the best interests of the child does not always occur in these particular cases (although they should) and social conditions that breed poverty and abuse may remain untouched. These authors have noted that in recent years, psychological evaluations of preadoptive relatives seem to be on the rise, suggesting that judges and caseworkers are recognizing the need to take a holistic look at families and children's needs.

In cases in which a non-biological and nonfamily person wishes to raise a child, this usually occurs by foster parenting or adopting a child. If the foster parent does not adopt the child, the state will continue to provide financial assistance to the foster parent while the child lives with him or her. If an adoption takes place, the parent is then on his or her own financially and state funding and coordination of beneficial services will cease. This occurs because once a foster parent (or any adoptive parent) adopts a child, then it is assumed the family will now function as any other family unit would, with parents financially and practically supporting children.

Forensic psychologists may be asked to perform evaluations to determine if someone is fit to parent or whether a particular foster or preadoptive parent will be likely to be a good match for a child. Sometimes the question for the forensic evaluator is an easy one. This might be 
where the child is already flourishing in a foster home, the foster parents want to adopt the child, and the biological parental ties have been broken. Here, the mental health professional must comment on the fitness of the foster family to meet the best interests of the child. These cases may be heard first in juvenile court where the state agency with responsibility for child protection has followed a permanency plan that resulted in the termination of the parental rights to the child. Family caseworkers following standards outlined in Public Law 105-89, the Adoption and Safe Families Act of 1989 may already be involved and the subsequent long-term foster care or adoption proceedings are simply a pro forma continuation.

In some cases, it gets more complicated, especially when a child has special needs in some way, when there are mixed races between the prospective adoptive parents and the child, or when gay and lesbian couples are the prospective adoptive parents. It is of course possible to challenge outdated state laws on these issues with psychological data indicating that there is no psychological evidence that gay, lesbian, or bisexual birth or adoptive parents intrinsically have a negative impact on the children involved; however, heated emotions, religious concerns, and conservative ideology may make it difficult if not impossible to overcome the myths in some areas. An example is a Florida decision to ban the adoption of one parent's biological child with her Lesbian partner, even though she had been co-parenting the child together with her partner, which demonstrates the difficulty in getting the court to base such a decision on scientific data.

In performing an evaluation for adoption, it is also necessary to include information about the adoptive parents' reasons for wanting to adopt the child, especially if it is not an infant. It may be important to know about their determination of infertility and ability to psychologically accept a non-biological child of a different age, race, religion, or culture, and willingness to provide for a child with special needs, if that is relevant. Information about why a particular child is available for placement may also be relevant, such as kinship issues, financial difficulties of the birth parent, health of the mother, or other reasons for her unavailability, such as incarceration. Now that adoption records are more accessible to both birth parents and adult children, newer forms of adoption are available, such as leaving records open at the child's birth instead of sealing them, arranging for adoptive parents to have structured or flexible contact with the birth parent, or keeping contact with cultural or kinship ties in international or interracial and transracial adoptions.

Most adoptions are handled by private and public agencies. These agencies have the responsibility to perform evaluations of adoptive parents and available children. Usually the court recognizes the work of the agencies and finalizes adoptions faster than if the evaluations are made through private attorneys and mental health professionals. Although the U.S. Multiethnic Placement Act of 1994 prohibits adoption agencies from receiving federal funds if they use race as a sole criteria for adoption placements, psychological findings indicate that a connection to a child's racial and ethnic heritage is important to healthy development.

The laws covering state and international adoptions are quite complicated and require specialization. In the seven-year period between 1988 and 1995, in the U.S. there were over 10,000 adoptions of poor, lower socioeconomic status toddlers who did not speak English as their first language, many of whom came with health and malnutrition problems. Bureaucratic red tape snafus caused many of delays in bringing these children to their new homes, creating even more psychological and developmental problems. Although some religious groups did help these adoptive parents to anticipate dealing with these children, most were not prepared for the extent of difficulties they would experience. Today, 13 countries have adopted the rules proposed by the 1997 Hague Private Law Convention on Protection of Children and Cooperation in Respect of International Adoption and the 1989 United Nations Convention on the Rights of the Child. After a peak in 2005, the rates of international adoptions have drastically declined, with only 5370 children from other countries being adopted 
by Americans in 2016 (Budiman \& Lopez, 2017). The United Nations has supported the development of children's legal rights around the world and serves as an important resource for those who work in this area. We discuss these legal rights for children further in Chap. 20.

\section{Intervention Programs}

The most recent reports indicate that parents and other caretakers are the most likely people to abuse a child. As has been the case for years now, the majority of those reported to have maltreated a child are women $(54 \%$, although this proportion is evening over the years), with an average age of 31 years old as compared to 34 years old for the men. About $69 \%$ of the children who were maltreated were abused by their mother, either acting alone (nearly $41 \%$ ) or with a father or a nonparent (28\%). However, it is important to remember that women spend more time with children than do men. Males are most likely to commit the serious, life-threatening physical and sexual abuse against children.

There are a variety of intervention programs for parents who are accused of abusing their children. The most common are the low-cost educational "parenting classes" that are usually run by local agencies who get referrals from the different branches of the court, in particular, the family and juvenile court systems. In some jurisdictions, and where providers are available, parent education training can be conducted in a one-on-one, more therapeutic format, although these do typically remain primarily psychoeducational and manualized in nature. Treatment programs for parents who abuse children tend to be much more expensive and difficult to find. Gold if the abuse was caused by or related to a substance abuse problem that the parent has, there may be community programs in the substance abuse community. If domestic violence coexists (there is a $60 \%$ overlap between child and woman abuse) battered woman shelters and court-ordered offender treatment programs may address the parenting concerns (Walker, 2017). But, if the abuse is because a parent is mentally incompetent to take care of their children, there are few programs available. Along with more discussion of different general intervention options, we will also discuss two model programs: a Florida program called OPTIONS for seriously mentally ill women who are involved with the criminal justice system, and the Southern California PROTOTYPES program for substance abusing and mentally ill women. The reader is encouraged to remember that these are to be considered as models only, although there are more of these programs available across the country than there have been in years and generations past.

\section{PROTOTYPES: A Program for Substance Abusing Women}

Many moms are unable to properly care for their children because they have a substance abuse problem that needs treatment. PROTOTYPES provides a residential program where moms and their children can live together while she learns to stay sober, gets help for any mental health problems, learns how to stay out of domestic violence relationships, and how to parent her children. The children are placed in school and mental health programs that include establishing good peer relationships which many of them lack. Both moms and children have difficulty attaching and bonding to relationships, so the program focuses on these areas, too. This is also a step-down series program with moms coming alone first after they detox and begin their substance abuse program. They add a domestic violence prevention component shortly after. If appropriate, they may be offered individual therapy in addition to the groups they attend. Women without vocational skills may also begin training programs once they are stable. A stepdown program reintegrating the mom and children together begins with supervised therapeutic visitation when the CPS caseworker brings the children to the PROTOTYPES center, increases to mom and children monitored in different activities, and finally, unsupervised or monitored time together when the children are returned to 
live with the mom and the PROTOTYPES residence. Once the women are discharged from the residential facility, they continue to participate with a caseworker and therapist where appropriate. In some other communities, like the program run by the Miami League of Women Voters, there is a stage 2 residential facility that provides even longer support for those who also experienced domestic violence.

\section{OPTIONS for Seriously Mentally III Women}

The OPTIONS program was begun as a day treatment therapeutic community for seriously mentally ill women who were involved in the criminal justice system. The 69 women who were a part of this intensive program had almost as many children together although some women had none and others had several. Most of their children were in the care of CPS or relatives, as these moms could not adequately care for them. As might be expected, most of these women had been abused as children or in their adult lives. Their diagnoses centered around schizophrenia spectrum disorders and bipolar and affective disorders in addition to PTSD. The women participated in a variety of group programs, including parenting modules, and those who had access to their children were encouraged to bring them in at specific times for hands-on parent training.

\section{Parenting Classes for Abusive Parents}

The assumption is made that an abusive parent will commit abuse or fail to prevent it from occurring if that parent does not have knowledge of what to expect from a child developmentally, does not know of discipline alternatives to corporal punishment, or uses the child to make up for deficits in his or her own life history. In fact, a large number of child abusers do need education about children's needs, and, for them, parenting classes may be helpful. However, another group of parents, usually women, fail to protect their children because they cannot even protect themselves from violent and abusive partners. These protective mothers may be forced to coparent their children by a family court that is insensitive to the danger both the mom and children are in when the dad is willing to abuse power to control them. We have discussed this earlier in Chap. 15.

Parenting classes are not sufficient or helpful here, either for the moms or for the dads who are court-ordered to attend. Especially in the case of fathers who are also abusing their spouses, issues related to power, control, and rigidity can be complicating factors in reducing child abuse rates. The dads need a more hands-on approach so that they can be told immediately when they are inappropriate or miss the signals their child is giving them, or to help them learn to be more flexible or to relinquish some of their control in a healthy manner. Many of them learn to repeat back in a rote manner what they are supposed to do but haven't a clue as to how to apply what they learn in real life. They need a step-down series starting with didactic parenting classes, then supervised therapeutic visitation, then supervised visitation, and finally short periods of unsupervised visitation with monitored pickup and return of children.

\section{Programs for the Elderly}

Although physical abuse is a problem with the elderly who are dependent upon caretakers who are untrained, unsupervised, or just worn out, it is neglect that poses the biggest challenge for communities today. The largest number of very elderly-over 80 years old-are women who live alone, are lonely, and do not have enough money to purchase sufficient food, medication, and other necessities of life. They are often unable to drive or to get around on their own as they approach 90 years old but if their minds are still active, they do not want to be sent off to assisted living centers. Few grown children are able to have their parents or grandparents live in their homes, and many live too far away to provide much assistance. There are some community programs that provide meals to seniors, 
and other organizations and religious groups provide some small amounts of home care, but basically the elderly in the U.S. tend to get little assistance as they age. In some locations, however, agencies and/or mental health providers have begun to visit ALFs or even elderly individuals who are still living at home in order to provide psychological services to assist with adjustment, depression, anxiety, and the many emotional elements connected to aging. Insurance companies such as Medicare often approve and pay for these services since improvements in psychological health of the elderly tend to lead to reduced costs for medical care. For example, a severely depressed person may not take heart medication regularly and may require frequent hospitalization, whereas a similarly-aged individual who is in therapy and less depressed may be more consistent with medications and suffer fewer medical complications.

\section{Mentally Challenged Adults}

Mentally challenged children are provided with special education programs until they turn 18 years old (in some communities the age is 21 years old) and then the state must take over providing them with services if the parents cannot do so. There are sheltered workshops and other vocational where they learn skills that may be helpful in the community, assisted living facilities and group homes, and residential centers for those who are too profoundly developmentally disabled to live by themselves in the community. The state does take responsibility for providing programs and protecting these citizens although most of the responsibility falls on the family.

\section{Individual Psychotherapy and Case Management}

Children who have been abused are often placed in individual therapy programs to heal from the abuse they have experienced. In the past twenty years, techniques to deal with specific problems commonly seen in abuse victims have been developed. They are too numerous to address here. However, it is important to note that like others who experience PTSD and associated disorders, these children need therapeutic assistance so that the adaptations and accommodations they made to protect themselves as best they could do not become part of their adult personality patterns (Ashford, 1999; Gold, 2000). Mental health centers, schools, church groups, and trained private practitioners are available to provide such services.

It is more common for adults who were abused as children to wait until they begin to develop chronic or serious mental health symptoms as adults before they seek therapy for their problems. Women and men do not always experience the effects of abuse right away, and in fact they might be okay for many years, sometimes developing specific problems when they become parents themselves. Like the exposed children, adults also have a choice of different treatment modalities although those in rural areas often have more difficulty finding trained clinicians (Courtois, 1999).

We still don't know why some people develop certain symptoms and disorders and others develop different ones when they were all exposed to the same type of abuse. In fact, we do not know why different children in the same family develop differently. For example, five children in a family where the parents were alcoholic and neglected them can turn out differently with some becoming educated professionals and others being unable to hold a job or stop their own substance abuse or domestic violence when adults (Gold, 2000). As we discussed in Chap. 10 on interventions in forensic settings, theorists who work in the field of substance abuse differ in whether the problem is viewed as an addiction, a disease, or a behavior control problem.

Most studies find a definite gender difference in the impact of child abuse with boys more likely to use violence in their own lives and girls more likely to be the abuse victim. In one such study boys who were exposed to violence in their family were 700 times more likely to become 
abusers. If those same boys were also abused themselves, the risk of becoming abusive was raised to 1000 times children who were not abused (Kalmus, 1979). New brain imaging studies have found problems with dysregulation of emotions and other PTSD-related problems in children who have been exposed to abuse.

\section{Civil Lawsuits}

In addition to treatment, some adults who were abused as children file lawsuits against their abusers. These cases are more successful when the defendant is not related to the plaintiff, such as the clergy, a teacher, or someone else with "deep pockets." If parents or other relatives are sued, it often causes serious splits in a family that make it difficult for the plaintiff to ever have a supportive relationship with some family members. If other children were also involved, it may give the plaintiff a natural support system. As difficult as these cases can be for the plaintiff, it also can be therapeutic to confront the abuser and force and apology. As we have stated in other chapters, a civil lawsuit can only give a plaintiff financial compensation for the damages he or she has experienced. Forensic psychological evaluations to document psychological damages are often required by attorneys who take these cases to trial.

\section{Summary}

In this chapter, we reviewed the laws that have been passed to protect children, the elderly, and others in protected classes who have special needs. The child protective services agencies throughout the country have been under scrutiny for their inability to protect children. Reasons for the difficulties include the social mores that protect the family unity and ignore many reports because of poor investigations. The youngest and least experienced workers are assigned to protect children and while many are dedicated to their work, their caseloads are enormous and the resources to back them up are limited or nonexistent. Children who are abused often give many clues but do not put it all together for the adults who could protect them. The relationships between them and their parents are complex and include both love and fear of further harm. They learn to accommodate to the situation, keeping the parent as calm as possible. Foster families are not a good solution for most of these children whose needs are great and resources are few.

Adding support to the mother or natural family is another possible way of offering them some protection. Adoptions are often a good way to help children find a good family. International adoptions and those with hard-to-place children challenge the system but when they work out, everyone is happy. Interventions with abusive families involve long hard work and often require protecting the child while the parent gets it together. Residential programs where mothers and children can come together to learn new ways of relating to each other seem to have good success rates. Battered women shelters, substance abuse treatment programs, and residential or day treatment programs for women with serious mental illness all help mothers deal with raising their children. Programs for men, however, tend to be less successful, perhaps because there are so few with hands-on experiences as compared to programs for women. Programs for the protection of the elderly as more difficult to locate and fund but do exist in certain communities. Other programs work with the mentally challenged and disabled populations that also need special protections.

\section{Questions to Think About}

1. Would harsher punishments for parents and caregivers help to reduce the maltreatment of children and the elderly? Or would greater access to resources and education be of greater benefit? Why do you think so?

2. Some argue that it is unfair (and even potentially discriminatory) that adoptive parents often have to undergo psychological evaluations to assess their parental fitness. What are your thoughts on this argument? 


\section{References}

Budiman, A., \& Lopez, M. H. (2017). Amid decline in international adoptions to U.S., boys outnumber girls for the first time. Pew research center fact tank. Retrieved from https://www.pewresearch.org/fact-tank/ 2017/10/17/amid-decline-in-international-adoptions-tou-s-boys-outnumber-girls-for-the-first-time/.

Centers for Disease Control. (2012). Child abuse and neglect cost the United States $\$ 124$ billion. Retrieved from https://www.cdc.gov/media/releases/2012/p0201_ child_abuse.html.

Felitti, V. J., Anda, R. F., Nordenberg, D., Williamson, D. F., Spitz, A. M., Edwards, V., et al. (1998). Relationship of childhood abuse and household dysfunction to many of the leading causes of death in adults. American Journal of Preventive Medicine, 14(4), 245-258. https://doi.org/10.1016/s0749-3797(98)00017-8.
Kalmus, D. (1979). The attribution of responsibility in a wife abuse context. Victimology, 4(2), 284-291.

National Incidence Study (NIS). (n.d.). Retrieved from https://www.childwelfare.gov/topics/systemwide/ statistics/nis/.

NCANDS. (n.d.). Retrieved from https://www.acf.hhs. gov/cb/research-data-technology/reporting-systems/ ncands.

United States Department of Health and Human Services. (n.d.). Retrieved from https://www.hhs.gov.

United States Department of Health \& Human Services, Administration for Children and Families, Administration on Children, Youth and Families, Children's Bureau. (2019). Child Maltreatment 2017. Retrieved from https://www.acf.hhs.gov/cb/research-datatechnology/statistics-research/child-maltreatment.

Walker, L. E. A. (2017). The battered woman syndrome (4th ed.). New York, NY: Springer. 